\title{
Using a "Socio-Cultural" Approach in Teaching Information Technology to African American Students with Academic Difficulties
}

\author{
Cameron Seay \\ Georgia State University, Atlanta, GA. USA
}

specws@langate.gsu.edu

\section{Executive Summary}

There continues to be a severe under-representation of African Americans in the fields of information technology (IT) and computer science. The author contends that this is attributable, at least in part, to inappropriate assumptions about the nature of thinking, knowing, teaching and learning. He contends that attention given to these assumptions can improve learning environments, not only for African American students, but also for students of all ethnicities who experience difficulty in the existing school culture. This article is the case study of a project that selected 15 African American students experiencing some type of academic difficulty. These students were selected not only because of their academic challenges, but also because they exhibited an intrinsic interest in computer technology. The students were placed in two single-sex groups for instruction in Web development. While the ostensible objective was to introduce the students to the cognitive tasks involved in Web development, the underlying objective was to teach students who appeared unmotivated in the mainstream school context to engage cognitively in a relatively sophisticated domain. The learning environment used to do this was "sociocultural" in nature, in that not only were the students exposed to the factual material and vocabulary needed for the domain (that is, from an objectivist perspective), and not only were the students allowed to work with this material in a way relevant to them as individuals (that is, from a constructivist perspective), but they were also allowed to help define the language of the classroom via peer learning and discussion. Such an environment was selected because of its potential to address the possibility of the learning environment being a "poor fit" for these students. Even though the contact hours were limited, it appeared that the girls quickly mastered the tasks and concepts required - and were able to articulate these concepts - while the boys mastered the tasks but did not appear to acquire the same mastery of the concepts as the girls. Much more work in this area is needed, but this case study indicates that the methodology used may not only facilitate a wider pool of African American students entering technology and science fields, but may also help students of various ethnicities that are struggling academically.

Material published as part of this journal, either on-line or in print, is copyrighted by the publisher of the Journal of Information Technology Education. Permission to make digital or paper copy of part or all of these works for personal or classroom use is granted without fee provided that the copies are not made or distributed for profit or commercial advantage AND that copies 1) bear this notice in full and 2) give the full citation on the first page. It is permissible to abstract these works so long as credit is given. To copy in all other cases or to republish or to post on a server or to redistribute to lists requires specific permission and payment of a fee. Contact Editor@JITE.org to request redistribution permission.
Keywords: academic performance, African American, computer science, constructivist, epistemology, information technology, Internet, motivation, programming, secondary school, socio-cultural, socio-historic 


\section{Introduction}

The fields of computer science and information technology are essential knowledge domains for the information-based economies of the $21^{\text {st }}$ century. Accordingly, they will be areas in which much of the decision making for these economies will occur. These are also fields in which there is a low representation of African Americans (Tapia, Chubin, \& Lanius, 2000). This paper is the case study of a project conducted at a charter middle school in the southeastern United States to investigate the usefulness of a "socio-cultural" learning environment to introduce a selection of African American students experiencing academic difficulty to the field of information technology.

According to the Bureau of Labor Statistics, less than 5.5\% of the nation's engineers and $8.5 \%$ of the nation's computer systems analysts and scientists were African American in the year 2001 (ftp://ftp.bls.gov/pub/special.requests/lf/aat11.txt). When one looks at the breakdown of academic majors, it is easy to understand. For example, in 1996 approximately 3\% of the Master's degrees granted in computer science went to African Americans, and less than 2\% of the Master's degrees in engineering (National Science Foundation, 1996). Advanced degrees are a good predictor of increased income potential over the course of a career. The National Science Foundation has issued a call for high schools, colleges, and research universities to do more to increase the level of participation in the field by women and minorities (Tapia et al., 2000).

Many African-American students experience academic difficulty during their encounters with the public school systems of the United States (Ogbu, 1992, 1995). It is quite possible that some of these difficulties are related to assumptions made about thinking, knowing, teaching and learning by those who make decisions about curricula. Often these assumptions drive decisions about the nature of public education - what will be its objectives and what will be its methodology. But the assumptions themselves are seldom brought to the fore and examined as part of the decision making process. Writers such as Hilliard (1994), Ladson-Billings (1994), Steele (1997) and Wilson (1991), have questioned these assumptions, in one way or another, and a substantial body of literature suggests that it is important to assess the assumptions made by the learning environment to gauge their efficacy for the learners in question.

What are these assumptions? They are sometimes overt and sometimes subtle. For example, one of the most popular constructs in the field of educational psychology is that of "self-efficacy," whereby a student's self-perceived mastery of a discipline is highly correlated to their performance in that field. There is evidence, however, that this construct is influenced by the culture of the student. Students of different ethnic backgrounds demonstrate varying orientations to selfefficacy (Eaton \& Dembo, 1997).

Another assumption that the mainstream American school culture makes is that standardized testing provides useful information about a student's progress in a discipline. This is not necessarily the case, and both the American Educational Research Association (http://www.aera.net/about/policy/stakes.htm) and the American Evaluation Association (http://www.eval.org/hst3.htm) have taken strong positions against putting too much emphasis on "high stakes testing." An emerging (but not new) testing methodology, based on item response theory (IRT), has a much narrower view of the trait or traits that are being assessed by testing (Hambleton \& Swaminathan, 1985). In both varieties of the IRT model - the unidimensional (one trait) or the multidimensional (more than one trait) - the abilities being assessed are fairly specific. This is in stark contrast to "norm referenced" tests like the Iowa Test of Basic Skills (ITBS), which is used to make global assessments of a student's cognitive development at a given point in time. Many critics of such tests, like Kohn (1993), say that schools are ill-advised to give tenyear-olds "standardized" tests, when most of the research about human development indicates that at that age cognitive development is far too erratic for such fixed measurement. 
IRT also counters two other prevailing assumptions of the school culture: 1) that including speed as a factor increases our understanding a student's level of expertise in a given knowledge domain, and; 2) that "norm-referencing” students against a base population's testing profile does the same. When African American students are given norm-referenced standardized tests, the information derived does not clearly inform us of any cognitive deficiencies- merely that there are substantive differences between them and the base population. This is not to contend that there are not achievement issues among African American students. But giving the students normreferenced standardized tests does not provide clarity about a student's cognitive development, only additional confounds.

Finally, perhaps the most damaging and persistent assumption is about the nature of intelligence itself. The American school culture still largely views intelligence - and the knowledge with which it interacts - from primarily an empiricist/objectivist perspective. In other words, intelligence is something that is dispensed by nature in relatively fixed quantities, and there is little one can do to affect this predetermined amount of intelligence. Knowledge is something that is external to the user: Fact A is the same Fact A for Person 1, Person 2 and Person 3. One of the primary functions of the school culture, then, becomes identifying the "smart" students, and holding high expectations for them, while keeping expectations for the "not so smart" students reasonable. The identification of the more intelligent and the less intelligent is performed via some manner of linear measurement. Since intelligence is a quantity, the reasoning goes, it can be measured. But learning theorists like Binet (Binet \& Simon, 1980), Piaget (Green, 1989), and Vygotsky (Wink \& Putney, 2002) saw intelligence as something much more complex and harder to define. Intelligence and knowledge was shaped not only by innate ability, but also by an individual's previous experiences and their environment. This gave rise to other theories about intelligence and knowledge that included the impact of personal experience and social context.

Modern educators claim they are moving away from quantitative constructs like "IQ," and to some extent this is correct. Constructivism is now accepted as a valid pedagogical framework. But the perception of intelligence as a quantitative construct persists nonetheless. It is this assumption, distributed throughout the mainstream school culture, which may be the most problematic for African American students, whose cognitive activity often does not manifest itself in a manner the school culture accepts as "intelligent" when assessed by quantitative linear measurements.

\section{African Americans and the School Culture}

Fordham and Ogbu (Fordham, 1993, 1995; Fordham \& Ogbu, 1986; Ogbu, 1992, 1995) have written extensively about the problems that African Americans experience in American schools. Ogbu has commented on the oft misrepresented "acting white" syndrome, by which American blacks that achieve academically are sometimes seen by their peers as cultural traitors as they acquire the social patterns required to succeed in the mainstream school culture. This syndrome is better characterized by Ogbu's label for it, an "oppositional frame of reference”: "Other minorities (usually involuntary minorities) that have oppositional cultural frames of reference are less successful partly because they interpret learning the school's cultural practices and language as a subtractive or displacement process, which is threatening to their collective cultural and language identity” (Ogbu, 1992, p. 293).

Fordham studied "inner city" high school students in Washington, DC, and their climb toward achievement. While her research is often cited as evidence of African Americans' repudiation of academic achievement, Fordham interprets her works as illustrating how much African American students are devalued by the mainstream culture, and that they wage an incessant struggle to maintain the integrity of their identity while participating in the mores of a racist school culture (Fordham, 2003). 
Steele (1997) has conducted numerous experiments on Stanford students, and written extensively on the role that stereotypes held within the mainstream school culture play, as African Americans work within its context. A recurring theme in his work is shaping the learning environments with subtle prompts as to what his expectations are for student performance. Invariably, such a treatment has a significant impact on the African American Stanford students, whereas it has little impact on the white students. Steele concludes that the repeated exposure to stereotyped expectations has a dramatically deleterious impact on African American students.

In terms of resource allocation, Darling-Hammond (2000) points out the issue is often not only inequity in expenditures, but also inequity in the expertise of the teaching staff. It is more often the case that poorer school districts get teachers ill prepared to teach the subjects they are assigned to teach. This is particularly critical when it comes to teaching technology-based subjects. Unfortunately, the people that develop an appropriate level of proficiency are much less likely to be attracted to teaching academically troubled students in predominately African American school settings.

Delpit (1995), Hilliard (2002), Ladson-Billings (1994), Wilson (1991), Woodson (1990), and many others have described how the inherent racism in American society has served to limit aspirations of African American students. My purpose here is not to add to those voices, but to address, via a socio-cultural learning context, how to counter these influences and help students acquire mastery in the domain of information technology. My intention is to build a technologyladen learning context in which the students are the central component. This goes much further than just making a lot of technology available; it is a conscientious and focused effort to intertwine the language of technology with the language of the students. By continuous use of the vocabulary of the technocracy, the students become a part of it. Further, because they have mastered some level of the language of technology they are able to directly impact it. They are then ready to join in the activity of creating what Vygotsky describes as the artifacts of distributed intelligence - computer programs and other technological innovations (Wertsch, 1985).

\section{Statement of the Problem}

This paper addresses two salient problems: 1) The difficulties many African American students have with the mainstream school culture, and; 2) The dearth of African Americans in the fields of computer science and information technology.

The problem of getting African American students more involved in the sciences is a symptom of a broader problem of African American school achievement. By the most commonly used measures, African American students are behind other ethnic groups in academic performance (Donsky \& Jones, 2002). Lacking the literacy and computational basics that are prerequisites for a career in the sciences, many African American students see fields like computer science and information technology as beyond their reach. Yet these fields offer some of the greatest opportunities for those that are equipped to take advantage of them, the current economic downturn notwithstanding. But students must be prepared for these opportunities, and not just in computer-related skills, but also in the more basic skills of mathematics and literacy. The literature has led me to the conclusion that these skills can all be built within a context the student finds of intrinsic interest.

Eisenberger, Masterson, and McDermitt (1982) suggest that increasing task variety can lead to students developing general rules concerning exertion of effort. That is, varying the external stimuli related to the associations in one knowledge domain can lead to a change in the way the students function in other knowledge domains. Hidi and Harackiewicz (2000) discuss the concept of "situational interest" or learning environments that provide a type of generic interest to a broad range of students. In theory, a learning environment that is of heightened interest to the student 
will lead to increased engagement, and, subsequently, to increased learning. We selected students who are experiencing difficulty with the learning environment of a public school, yet have exhibited, by loose criteria, an interest in computer technology. My initial intention was to give them detailed instruction in computer science and information technology, but time constraints forced me to focus just on an area of information technology. By "detailed instruction" I mean that the students would be given instruction in how to function in the domain of information technology, and begin the journey of developing expertise in that domain.

\section{Ways to View Teaching and Learning}

Greeno, Collins, and Resnick (1996) outline three epistemological perspectives as a framework for the analysis of teaching, learning, thinking, and knowing. These three perspectives are the empiricist (sometimes called objectivist) perspective, the rationalist (sometimes called constructivist) perspective, and the socio-historic (sometimes called socio-constructivist, socio-cultural, or situative) perspective.

As defined in this framework, an empiricist perspective sees knowledge as a phenomenon that exists external to the learner. It consists of mastering associations between and among the objects that comprise reality - a multiplication table, for example. One "learns" by deepening and expanding one's understanding of these associations. Assumptions stemming from this perspective would include that standardized assessments are a good indicator of domain mastery. A rationalist perspective sees knowledge as existing in the mind of the learner as he or she interacts with the learning environment. Knowledge is "constructed" (with the learner's prior knowledge as a reference) in the process of this interaction. Assumptions stemming from this perspective include that how a student interacts with the domain itself is a good indicator of domain mastery (a portfolio is an example). A socio-historic perspective sees knowledge as existing in the relationships among society's members and in the artifacts society creates. Learning occurs as the student engages in social activity and becomes a member of the communities of practice. Assumptions stemming from this perspective include that the creation of an authentic artifact of the domain is a good assessment that the student is becoming a member of the "community of practice." A sophisticated piece of software is an example of such an artifact.

One way of viewing these perspectives is as co-equal entities that make different assumptions about the phenomena of learning. In this view, the empiricist, rationalist, and socio-historic view each have a different take on the nature of knowing, thinking, teaching and learning, but they are different perspectives of the same phenomena. Another approach, and one that Greeno et al (1996) suggest, is that the socio-historic approach is a mediator of the other two - it resolves the conflicts between them and compensates for the inadequacies of each. In short, the socio-historic perspective has as its unit of analysis the historic event, and in this event are contained both the associations that comprise knowledge (from an empiricist perspective), and the interactions of the learners with the learning environment (from a rationalist perspective). It adds to this the concept of "the collective intelligence" of Vygotsky, the idea that intelligence is manifested by human interaction (Wertch, 1985). It is my contention that if we are attentive to the assumptions made by each of these perspectives and look for the strengths and limitations of each of them, we can create learning environments that will better meet the needs of a broader spectrum of students.

I have used the term "socio-historic" when describing the perspective as outlined by Greeno, Collins, \& Resnick. For my purposes, I prefer the term "socio-cultural" because of its connotation of a focus on cultural matters. I also prefer the term "constructivist" to rationalist because I find it used more commonly in the literature. This paper uses my preferred terms hereafter.

When it comes to African American students, especially those with academic difficulties, these perspectives can become useful tools for instructional design. It is not so much that the empiri- 
cist/objectivist approach is wrong as that it is incomplete and not applicable in all situations. Piaget observed that in problem solving, the solution the student came up with was not solely a function of the factual conditions of the problem set, but the previous experiences of the student and her stage of cognitive development (Green, 1989). Binet, much earlier, noticed the same thing when analyzing the wrong answers that students offered when he gave them cognitive assessments (Binet \& Simon, 1980). What appeared to be happening in both cases was that the learner was "constructing” knowledge based to a large extent on their prior experiences.

So we can see the utility of the constructivist perspective in explaining how we learn. The factual basis of knowledge is important, but this factual basis only becomes knowledge when a learner puts it in a relevant context. This is a personal context, because it is the learner who establishes it. It is the socio-cultural perspective that sees this learning as expressly and invariably a social activity. Learning is the process of interactions by people in the social context; human activity never occurs outside of this context. Learning is accomplished as the learners participate in the communal cognitive activity. Intelligence, then, is seen as distributed across the social context. It is contained in the activities carried out by the social participants and within the artifacts created by these participants - buildings, literature, university curricula, computer programs and computers.

What happens to many African American students is that their participation in this community of learners is marginalized by a number of social factors, including but not limited to American racism. For example, what the "Ebonics" debate of a few years ago failed to clarify was that students develop speech in a context that is valid for them (Shuy, 1979). This is not to say that the home speech of African Americans should be made the standard language of the classroom (when this may not be in the long-term interest of the students). But their home speech must be accepted as valid. If, as Vygotsky said, all learning starts with language, and if the only language these students have is marginalized by the school culture, their alienation from the school culture begins at their first encounter with it. A socio-cultural approach to the learning environment embraces students as valid cognitive beings in need of extending (not re-creating) their existing cognitive toolkit to include the skills that are required to function meaningfully in the world. So it is not that African American students should not be taught standard English (and later possibly computer science), or not accept standards of academic achievement; it is that African American students should not be invalidated and marginalized in the process.

\section{The Instructional Philosophy of this Project}

My task was to coach African American students (almost all having academic challenges in the school culture) in an intellectual culture framed primarily by non-African Americans. A sociocultural framework, I theorized, would facilitate this because of Vygotsky's work in establishing that all learning was first accomplished through the interchange of language among the learners (Wink \& Putney, 2002). The students in this project would be in continuous discourse with the instructor and each other. They would be scaffolded in clarifying their expectations for the class and for themselves. Discussion and question/answer sessions would be repeated throughout the instruction. This would allow students to exchange ideas, and allow the learning environment to become laden with a context that they themselves had helped to establish.

The major shortcoming of the mainstream academic environment in America, when dealing with the African American population, is insufficient attention to the importance of the social context. The socio-cultural perspective sees language as the primary driver in learning. African Americans, especially those from poorer, less literate backgrounds, often have their identities compromised in that they bring to the classroom environment language patterns that are considered unacceptable (Fordham \& Ogbu, 1986). This often starts a long-running drama; culminating in what Ogbu (1995) calls the "oppositional identity" - lower achievement, and higher dropout rates. 
Van Merrienboer (1997) suggests that when designing an instructional environment to teach a complex skill (like computer programming), the skill should be decomposed in such a way to facilitate the learner putting together the pieces when the skill is to be used. This approach is something of a departure from how the school culture teaches skill acquisition, in that schools in general teach disparate, disconnected skills. It is left up to the learner to later put these disparate skills together so that she can use them in solving problems situated in a given domain. For example, in my observations at the charter school, apart from arts education, students were taught the traditional subjects in the traditional way. Even though the school was staffed by a complement of highly motivated, skilled teachers (all of whom volunteered for service at the school), they were still held accountable for standardized test scores as a measure of performance. According to van Merrienboer (1997, p.3), training for complex cognitive tasks and teaching academic subjects are very different in nature. This condition, I contend, is merely a manifestation of school organization and not inherent to instruction. There is no reason that school subjects, particularly from the middle school grades on, cannot develop proficiency in ways that learners will use later as practitioners. Particularly for students with skill deficiencies, I submit that it will be helpful for them to acquire the skill in a context meaningful (and of some intrinsic interest) to them. There remains the issue of transferring the skill to another cognitive context. But for a skill like literacy this should not be a problem. Text decoding is readily transferable from one domain to another. Transfer of math skills across domains may be more of a challenge. But Anderson, Reder, and Simon (1996) present arguments that whether or not a student will be able to transfer math skills from one context to another depends on the instruction.

Van Merrienboer (1997) breaks down the components of a complex cognitive class as follows: algorithmic methods, prerequisite knowledge, heuristic methods, supportive knowledge, part-task practice, just in time presentation, whole task practice, elaboration and understanding. The implementation of these components, in concert, will allow the learner to function in the domain as a practitioner. So something like coding a Web page in HTML could be broken down to identifiable constituent tasks - understanding HTML syntax; creating files in a text editor; uploading files to a Web server; debugging the code - and then combined to perform a complex cognitive task: Web development. This process is easily identifiable to anyone who has ever taught Web development. My plan was to take these fairly objectivist procedures, and use them in the language and with the cooperation of students for whom the school culture (with its objectivist methodologies) is often an uncomfortable place. They are in this program of their own volition; as they participate, their progress is whatever it is. There are no benchmarks, other than a steady progression toward competency in the domain. They are all different, so their progress will be different. But it will be progress nonetheless. If they remain in the program, they will be successful. They will determine the nature of this success, because it will be based on who they are, where they come from, and what they want in life. Of course the instruction must move them forward toward domain competence, and at an observable rate. But much like the speech they acquire- if not effortlessly then quite naturally- they will acquire proficiency in the domain of information technology because they will interact with it. They are not competing with their fellow students. They will be assessed, by articulating in a combination of their own words and their newly acquired vocabulary, on what they have done, how they have done it, and how well they understand what it is they have done. Where their current speech is widely divergent from the language of the Academy, they will acquire the language of the Academy the same way they acquired their first language: by exposure, context, scaffolding, prompts, and respect for their innate cognitive ability. Thus they will become participants in the community of practice of information technology.

\section{Related Work}

Much research has recently been performed using socio-cultural contexts, often involving African Americans. There has also been much on African American students and technology. I was un- 
able to find, however, a large body of research specifically addressing African American students with academic difficulties in a socio-cultural context, using technology as a learning tool. Nonetheless, much of the work I did find appeared to be directly related to my project.

For over 20 years, Kenneth Hill's Detroit Area Pre-College Engineering Program (DAPCEP) has been working with African American youth in the Detroit area, giving them extensive training in mathematics and the sciences. While this program is not explicitly socio-cultural, it does allow students to become a part of the "community of practice" in science and mathematics. The students enter his program in middle school, and receive 3 hours of training in mathematics and science on the weekends. It is Hill's contention that this increase in contact hours, coupled with competent instructors, is what makes the difference for his students. Over ninety percent of the alumni of this program go on to college, and sixty two percent pursue technology-related degrees (Mercer, 2002). However, while this program targets African American students, it does not necessarily focus on those with academic challenges.

In an analysis of over 15,000 students, Owens and Hersholt (1998) found that male students used computers more often than female students in their science and mathematics classrooms. Female students, however, reported using calculators more often than males in their mathematics classrooms. Owens and Hersholt also found, perhaps surprisingly, that African American students used computers more often than Hispanic and white students in their science classrooms. They also found that African American students reported using computers more often in their mathematics classes, while white students reported using calculators more often than Hispanic and African American students. An explanation they offer for the higher computer use in certain areas by African American students is that it may result from teachers using the technology to increase lower standardized test scores, but there is no empirical substantiation for this.

Fazarro (1999) gives an example of a common approach when addressing issues of motivation with African American students. Working as a teacher of technology with academically troubled African American students, Fazarro cites the fractured state of the nuclear African American family and the learning styles of African American students as contributing factors for poor achievement by his students. While apparently conscientious, I feel Fazarro misses an important point: it is too often the position of educators that they must "fix" African American students so that they will better fit into the school culture. What is not understood is that the assumptions of the mainstream culture about these students are perhaps inaccurate. It is assumed, for example, that the school culture as it exists knows what serves as optimal instructional design for students that appear to be unmotivated. Yet there seldom exists a means to determine if there is a match between what the students need and what the environment provides, nor is there usually a way for the students themselves to drive the learning toward their interests. Fazarro (1999) suggests that teachers make special effort to cater to the needs of African American students. It is implied that such efforts are not needed for other student populations. He suggests, for example, that teachers "continually build their [the students'] self-confidence (and along will come their self-esteem).” The assumption is that a teacher knows how to do this a priori, for students with whom they share little cultural identity, and that by "building their self-confidence" issues like skill deficiency and poorly designed curricula will be addressed.

\section{The Project}

The objective of this project was to take African American middle school students, who were experiencing consistent failure in the mainstream academic environment, yet were intrigued by computers, and help them engage the academic environment. While the contact hours in the project were limited, it is hoped that this project will serve as a pilot for later, more comprehensive projects, ultimately leading to multi-year programs specifically for the type of student addressed herein. 
Eisenberger et al (1982) give credence to the position that reinforcement (reward) of intellectual effort in one area can lead to a generalized increase in effort in other, related domains. All of the student participants in this project had in some way indicated an interest in computer technology. The hope, reinforced by literature in this area, was that allowing these students to operate in a domain they find personally satisfying, and helping them experience success in this domain, would lead not only to the development of expertise in that domain, but also to an improvement in their overall school experience. In addition, African Americans are very much underrepresented in the fields of information technology and computer science, and another hope was that increasing exposure to the field among African American students could lead to future computer scientists and information technology practitioners.

The education literature contains much that suggests that a "direct instruction" approach, often with content of little intrinsic interest, serves to alienate students from the learning process (Kohn, 1994). Most IT corporate training uses a direct instructional design model, similar to that of Dick \& Carey (1996): clearly identified modules, each containing formal objectives, with little consideration for individuality or cultural context. My intention was to use frequent authentic, lowstakes assessment, usually in the form of written reflections by the student, on what they have experienced in the classroom and of what relevance the material is to them. From these reflections we can gauge the level of intrinsic interest for the student, and if this interest appears low, we can adjust the material or instruction as needed. In this case, the students appeared intrinsically motivated to master Web development because they felt it was "cool." More formal assessments would be of the students' actual work: the Web pages themselves. For students who had experienced considerable failure in the academic environment, to be able to work autonomously in a technology-rich environment could be viewed as tangible proof of their academic viability. Ogbu stated that the "oppositional identity" stems from students being forced to excel in a culture that has little personal value for them. This project was entirely voluntary, and the students could withdraw from it anytime they wanted to.

\section{Student Selection}

The students were selected from a publicly funded charter school in a large school district in the southeastern United States. This particular school was chosen because its theme was an "artsbased" education, for students who were encountering difficulties (ranging from mild to severe) in the mainstream public schools. The total student body was about 150 students, in grades 5 through 8. I first spoke with the Director of the school on January $28^{\text {th }} 2000$. She is a former public school teacher, whose motivation for starting the school was her experiences with using the arts with special education students. I told her that I was looking to implement a program to both improve the overall school experience for struggling students and help guide more African American students toward the disciplines of computer science and information technology. She enthusiastically embraced the idea and suggested I come out to see the facility and meet some of the students. On our first meeting, I outlined to her my thoughts on how the project should proceed. I felt that if we selected students who indicated some interest in computers, we should try to leverage that interest into a broadening of the students' interest in school overall. After some discussion, we decided to leave the criteria as to what constituted "interest" up to her and the teachers. We set the beginning of March of that year as the start date.

I made it clear from the onset that I was not interested in students with outstanding, or even good, academic records. I wanted to work with students who had experienced very little academic success, but seemed to be interested in computers. The Director notified all teachers about the project, and requested potential candidates from them. The school selected 15 students, 7 boys and 8 girls for the project. With the exception of one, all were either in the seventh or eighth grade. One fifth grade student, the daughter of an educator, was included even though she was experiencing 
only very mild academic difficulty. She did not seem out of place, and was allowed to participate. All of the other students had some type of school-related difficulty, either academic or behavioral. Several of the students had been retained a grade, and one was officially labeled as "reading disabled.” For the purposes of this project, the specific difficulty of each student is not really important, except to say that none seemed to be the result of any observable mental retardation or neurological condition. For myriad reasons, these students were having difficulty flourishing in the public school culture. Their parents or guardians had sought out this charter school in hope of better prospects for them.

The criteria for what constituted "interest" were left intentionally loose for several reasons. It was not my intention to devise an instrument to assess interest in computer technology, such as the one used by Hutchinson (1987) with a project similar to this one for high school students. I agree with Binet and Simon's (1980) suggestion for having assessors include their spontaneous judgments when giving their intelligence assessments. I was comfortable with the officials of the school (or parents) identifying students with academic problems who seemed to be intrinsically interested in computer technology. I also conducted interviews with each potential candidate for the project, to make a final determination of whether to include them. If there is concern that certain students may be left out by using such criteria, I would submit that we give all students who are struggling academically an opportunity to, in their own words, demonstrate an interest in computer technology. The program is always intended to be voluntary, so if a student's interest wanes, they are free to leave.

The questions I asked the students at the interview (see the section "Final Preparations") were offered by a developmental psychologist who specialized in adolescents, and an educational anthropologist. I would like the reader to keep clearly in mind my objective: it was not to derive "objective" measures, qualitative or quantitative, of "success". Rather, I seek to iteratively refine a method of instruction that will help in the development of a socio-cultural learning environment in which the students' overall academic performance improves. I will add pre and post test measurements in later implementations, merely to demonstrate skill acquisition. The ultimate test will be if, over time, students who were alienated from the school culture become able to productively function within that culture, and whether that culture becomes able to adapt itself to their needs as human beings. The program is voluntary, so if students are attracted to it merely because it seems "cool" that is of little, if any, concern. In fact, that is actually my objective.

\section{The case for single-sex classes}

This project had no external funding, and I initially intended to select a small group of boys to work with. There is much in the literature to indicate advantages in single sex education (Gurian, 2001). The students with whom I would be working were adolescents, and I felt that the distraction of coed classes would add an unneeded complication to the project. Once my intention to work with only boys was made known, one female teacher was very much against this plan. Her contention was that it would be unjustifiable to work with the boys and exclude the girls. I tried to explain to her the limitations involved, but she was adamant. After making the best case I could, I finally could not come up with a good enough reason to use only boys, and decided to include a complement of girls. As will be seen later, this was a very fortuitous decision. I did keep the boys and girls separate since, while my initial interest was focused on males, my exposure to the work of Caspi, Lynnam, Moffit, and Silva (1993) and Ge, Conger, and Elger (1996) and others led me to believe that the most interesting results would be derived from observing the students in single sex classes.

Several important authors in developmental and educational psychology have focused on the differences between males and females in the Academy. Fordham (1993) points out in "Those Loud Black Girls" that African American females must contend not only with racism, but with sexism. 
This is particularly relevant in the Academy, where social position plays such a vital role in how one interacts with the learning environment.

Oyserman and Bybee (2002) discuss the concept of "possible selves", used to explain how students view themselves, their social position, and what they perceive as the possibilities for achievement in their social context. They have persuasively demonstrated that the concept of possible selves is strongly gender differentiated for African American youth. While African American males may be seen as the "four d's" (dangerous, deviant, dumb, and deprived), African American families are more likely to have higher expectations for their daughters and provide greater supervision for them (Fordham, 1993). This may manifest itself in a higher academic achievement for the girls (which is what led me to exclude them initially from my project) but nonetheless may contribute, paradoxically, to their underachieving because of the complicated nature of their social status. The developmental psychologists in my department assured me I would find the classroom interactions of girls the ages of my students in single sex classes very interesting.

\section{Final Preparations}

About three weeks before the start of the instruction, I interviewed each of the selected students to become acquainted with them. The questions I asked each are as follows: 1) What kind of person are you? 2) What do you think about school? What do you like about it? What do you dislike about it? 3) What kind of student are you? 4) What do you know about computers? Do you have one at home? 5) Where do you see yourself in 5 years?

A sample interview with one of the students (who would emerge as a leader of the boys):

JD, seventh grade male, 13 years old:

Q: What kind of person are you?

A: Laid-back; hate boring stuff; hate to be in the house

Q: What do you like/dislike about school

A: Like the atmosphere (it's laid-back), I don't have as many enemies here, I like photography [the school has an extensive photo lab]; I dislike language (it's boring), I don't like math (it's boring)

Q: What kind of student are you?

A: Average, satisfactory.

Q: What do you know about computers? Do you have one at home?

A: I have one at home and I get online with it.

Q: Where do you see yourself in 5 years?

A: I haven't thought about it yet.

In the course of the interview, I explained to the students what the program entailed. I made it clear that this program was voluntary, both on their part and mine. If at any time they decided they no longer wanted to participate, they would be excused without any further discussion. On the other hand, if they were disruptive or uncooperative, they would be asked to leave.

After interviewing the students, I contacted their homeroom teachers to get a teacher's opinion of them. My interview with JD's homeroom teacher, Mr. R, was indicative of the rest: JD was interesting and very, very intelligent. He was a decent student, but was obviously working far below his potential. He posed something of a behavior problem in class, perhaps due to boredom. Mr. R's overall opinion of him was positive (as were the overall opinions of the teachers about all but one of the students). I had all of the students have their parents sign forms of consent to allow them to participate in this project. 
The charter school had no Web connection. (It would not be installed until after the school year.) A major computer manufacturer donated 21 computers, which could not be linked to a local Web Server. I ended up having to put freeware Web servers, FTP servers, and FTP clients on each machine. This would enable each student to work as if they were connected to the Internet, even if all of the pieces were on their workstation. They would still get the feel of downloading, uploading and viewing files from a Web server with a browser. But explaining to them the nature of the environment in which they were working would provide an opportunity for them to observe a very real problem faced within the domain, and the means by which we attempted to resolve it.

\section{The Instruction}

We had to identify the cognitive components that needed to be developed, and then determine what these components would consist of in terms of the domain of information technology. In other words, what would we teach, and how would we teach it?

Web development lends itself to clearly identifiable skills to master in order to gain expertise. Basic computer skills include file creation and management and the use of common applications. The students would also need to know the basics of how the Internet worked (TCP/IP, HTTP, FTP, etc). If one is to become a member of the community of practice in information technology, one is expected to have such understandings.

The length of instruction was initially intended to be for 6 weeks, with one hour, three days per week. However, because the instruction was not seen as "academic" enough (it was interfering with the students' preparation for the state-wide standardized tests), I was only allowed to see the students twice a week for an hour each time, and only for 4 weeks. This left only 8 sessions, which was wholly inadequate, but I resolved to at least get the project started with the prospect of continuing it the next school year. The Appendix shows the curriculum for the abbreviated period. The instructional template for the original six week, 3 hour per week curriculum is too long to be included here, and is available from the author.

The sessions were to be on Tuesdays and Thursdays, at 10:00am for the boys and 11:00 am for the girls. The first day started rather rough for the boys' session, a little smoother for the girls' session. This may have been attributable to my not having extensive experience with this age group. In consulting my notes after class, I felt that I might have overwhelmed them with too much unfamiliar jargon. Though I had an introductory period where we all shared our names, backgrounds, and expectations, the blank stares I received gave me cause to believe I was not letting them take the class where they wanted it to go. I made a note to myself to apologize the next class session and see if I could address those blank stares.

I began both next sessions with a frank apology for talking at them and not with them, and then just let the conversation revolve around computers in general, how the students saw them used and in what contexts, how they were used in the school, and what the students thought they could use this technology for. Several of the students were interested in digital music, and I assured them that if time permitted I would show them a few things I knew about digital music. They appeared to find this of interest.

I kept the same schedule for the girls and the boys, but the sessions were noticeably different. With the girls, it appeared I was only a character in their ongoing saga (with, I might add, several subplots involving who was friends with whom, and contentions arising when more than one girl liked the same boy). With the boys, I was more of the "sage on the stage." They seemed to want me to provide information for their consumption. They picked up on the mechanics of the tasks with little trouble; they just seemed to have a harder time incorporating the discrete tasks into aggregated activity. As the sessions went on, the girls seemed to grasp the material better than the boys. Of course I had no tools from which to draw other than anecdotal inferences about this. It 
could have been that I actually did teach the two sessions differently. It could also have been that even though both groups were similar in socioeconomic status and school performance, there may have been a substantive difference between the groups, other than gender, that I missed. It is unwise to try to read too much into these perceived differences with so few students, but the fact remains that much in the literature supports the possibility that the difference between the sections was significant. It is a tantalizing prospect to replicate this project with bigger groups, include coed sections, and use different combinations of male and female teachers and classes.

The salient feature of this form of instruction is the continuous writing and articulation of the students on their experiences in the learning environment. These students, who were problematic to the school culture in many different ways, were seldom a problem to work with. One girl, KW, who was labeled as having a "behavior disorder", tried to pick a fight with another girl once or twice, but after I made it clear she would have to leave, she reassigned her seating and was no further trouble.

I did notice, however, that the girls seemed much more verbal, both with each other and with me, than the boys. The developmental psychology professors in my department provided anecdotal evidence that this should not be a surprise, since adolescent girls in this society tend to be more verbal than boys. The boys seemed more reluctant to ask for help, but several of them emerged as leaders and the peers seemed more comfortable working with them than with me.

As for the peer tutoring, I was very pleasantly surprised at how well the self-formed groups interacted. Friends worked with friends, and what appeared to be a healthy competition emerged among both the boys and the girls. I made sure every student was a part of a group - even if it was only a group of two. PG, one of the quieter girls who expressed herself very clearly in writing but was very shy (she did not appear to be one of the more popular girls), had to try a couple of groups before she found a girl with whom she could work. Her partner, KW, who was an aggressive girl and very unsuccessful as a student, would often defer to PG for skill acquisition. Both girls grew considerably in confidence in the domain, and after four weeks they were together probably the most skilled group (KW had a very good eye for graphics, and PG picked up on the coding very quickly).

At the end of the fourth week, the students had assembled presentable Web pages. Because they were coded in HTML, the designs were simple, but skill nonetheless shone through. KW, the girl labeled with a "behavior disorder" showed unusual imagination in where to put her graphics. One of the boys, RW, who was labeled as reading disabled, emerged as a technical leader for the boys (JD emerged as the social leader). I was intrigued by RW's ability to know what certain words said on the screen, when all of his reading assessments indicated he was unable to read them. I asked him how he did it. He said his mother was a computer professional and she told him what the words were. I assumed he just memorized them, "whole word" fashion, and this allowed him to have a certain level of proficiency. He was then able to reproduce them on the keyboard in a meaningful context.

\section{Discussion}

Nothing in any of the literature could have prepared me for how quickly the girls picked up on the concepts of Web development. After some initial "I don't want to sit beside her, "and "she's always talkin' about me," when I allowed the girls to handle the seating assignments themselves, they took the work very seriously. Several leaders quickly emerged, and the girls seemed to have no problem collaborating (within their self-appointed sub-groups that is). Each session I would ask them to explain to me concepts that we discussed during the previous session. Without exception, all of the girls seemed to understand the concepts completely (van Merrienboer's "elaboration and understanding” component). PG, who was very introverted, took great pride in being 
able to upload her digital picture to the makeshift Web server and view it through a browser. KW, who had displayed aggressive behavior, demonstrated unusual acumen in selecting and placing Web graphics, and because of this, she would help the other girls who seemed to have difficulty in getting their pages to work.

And the girls' mastery of the subject matter went beyond just remembering vocabulary. They gave articulate explanations of the difference between the Internet and the World Wide Web ("the Internet is where you put everything, but the Web is where you use Web pages"), and demonstrated other conceptual understandings that appeared to be a substantial gain from their knowledge at the start of class. They demonstrated many of the techniques that IT professionals use to acquire and improve their skill sets: collaboration, seeking resources, trial and error, etc.

The boys, on the other hand, learned the basics of Web page construction, but seemed to be behind the girls in the depth of their understanding. However, there were several interesting developments among the boys. JD and RW emerged as leaders for the boys, and both had the highest skill levels among them. In fact, RW was probably the most advanced in terms of computer use among the girls and the boys. It wasn't until after the second or third session that I found out that RW was identified as reading disabled. When functioning in the domain (ftp'ing documents, for example) he evidenced no difficulty in processing the text needed to perform the task. He actually took the lead in a session on text editing. I can only attribute this to his knowing the interfaces (Microsoft Notepad, for example) to the extent that he would use whole-word memorization to figure out what to do.

Vygotsky described a "zone of proximal development" (ZPD) where a learner can perform with scaffolding beyond where they could perform without it. Eventually the scaffolding can be removed, and the learner can function independently at the new skill level (Wink \& Putney, 2002). I saw glimpses of this, and often it was the sub-groups doing the scaffolding and not the instructor. I do not want to mislead the reader: this study was so short and so limited in scope that I hesitate to draw any generalized conclusions. But I did see focus, engagement, and pride in the students' work. All completed a small website using straight HTML rather than an editor (like Front Page), and uploaded and downloaded files via FTP. Most mastered the concepts of FTP ("that's how you move things from where you are to the other computer...”), TCP-IP ("that's the language of the Internet"), and HTML ("that's the language of the Web."). I witnessed none of the disruptive behaviors seen in their regular classes (with the already-mentioned exception of KW).

These were students that for various reasons faced special challenges in the school culture, and our objective was to teach them a specific skill. I feel confident that with a year-long course in IT of 3 hours class time per week, and proper instruction (meaning that the course content is kept in a context meaningful and interesting to them), each of the students in these classes would make enough progress in the domain of IT to enable them to function independently and with a high degree of expertise. What we have to understand is that with that expertise comes proficiency in related skills like literacy and mathematics. If students are truly interested in computers, even if they have existing skill deficiencies, in the pursuit of that interest they will master the constituent skills required to participate in it. And the constituent skills required to function in computer technology include skills that will allow the student to succeed in other areas of the Academy.

The question will rise as to the merit of my anecdotal findings without any firm metrics to determine the source of the gains, if they can be considered gains. Also, these classes were somewhat smaller than the students' regular classes, and they may have received a higher level of attention than in their regular classes. Only replications with different scenarios can allow us to draw substantive conclusions. But if the perceived increase in intrinsic motivation (driven by our loosely defined "interest") is not only perceived but factual, and if it is due to smaller classes and increased attention by a technology instructor, then so be it. If the gains can be proven over time 
(by an overall increase in performance in school) then the technology community is morally obligated to provide the resources to help these students, who, with proper scaffolding, can make their own contributions to society.

\section{Conclusion}

This project touched on several topics in motivational research and the development of expertise. Khon (1993) and Chance (1992) have debated for years whether students should be given tangible rewards for performance. There were no tangible rewards given in this study, but the students met all expectations that I had in terms of performance (and the girls exceeded my expectations). With the one cited exception, there were no disruptive incidents, and the students worked on-task for unbroken 20-40 minute intervals.

Fordham and Ogbu(1986) have done considerable analysis on the phenomena of African American students not achieving academically for fear of "acting white.” I did notice, in both classes, some resistance at being perceived as "bookish" for fear of being "uncool." But there was complete and unreserved acceptance of the overall goal (Web development) as being of immediate interest to the students (cool enough, I guess). My contention is that if we seek to make school relevant to the individual student, as Dewey (1916) said we should, we would have far less difficulty with motivation.

Overall, however, this project was very inadequate. There needs to be much more work in several areas. For example, we have to operationalize (either qualitatively or quantitatively) what I perceived as mastery of the material in order to come to objective conclusions. I don't propose that we use a multiple-choice paper and pencil assessment to do this, but I do feel that we must be creative to allow the students to show what they have learned. Perhaps a unit project of some sort would allow the students to both work collectively and demonstrate proficiency.

In addition, this project needs to be conducted for a much longer period, maybe longitudinally. We need to determine if the perceived superiority of the girls, in terms of depth of understanding, has generalized validity. Also, because of the program's brevity I did not assign homework assignments to the students. But as practitioners the students will have to do considerable independent study to keep up with the continuous innovations in IT. Items must be added to the curriculum to address this. Also, we need to have more sections of the classes to include coed sections to see the benefits, if any, of single sex classes.

Because this project occurred late in the school year, there was not sufficient time to determine if the students' efforts in information technology carried over to their other classes. I did conduct follow up interviews with the teachers after the project was over. These, however, were done during the summer break when class was over. Several of the teachers did comment that the student in question was no problem for the rest of the school year, but this could be attributable to any number of factors (the prospect of summer and no school for one).

It is obvious that much more work needs to be done to draw firmer conclusions about working with this student population. If we as educators are serious about directing more African American students, especially those who may be experiencing academic difficulty, into technical fields and the sciences, I am convinced that this approach holds considerable potential.

\section{References}

American Educational Research Association (2003). Retrieved October 11, 2003 from http://www.aera.net/about/policy/stakes.htm

American Evaluation Association (2003). Retrieved October 11, 2003 from http://www.eval.org/hst3.htm 
Anderson, J. R., Reder, L. M., \& Simon, H. S. (1996). Situated learning and education. Educational Researcher, 25 (4), 5-11.

Binet, A, \& Simon, T. (1980). The development of intelligence in children. Nashville, TN.

Caspi, A., Lynnam, D., Moffit, T. E., \& Silva, P. A. (1993). Unraveling girls’ delinquency: Biological, dispositional, and contextual contributions to adolescent misbehavior. Developmental Psychology, 29 (1), 19-30.

Chance, P. (1992). The rewards of learning. Phi Delta Kappan, 73, 200-207.

Darling-Hammond, L. (2000). New standards and old inequalities: School reform and the education of African American students. Journal of Negro Education, 69 (4), 263-287.

Delpit, L. D. (1995). Other people's children: Cultural conflict in the classroom. New York: New Press. Distributed by W.W. Norton.

Dewey, J. (1916). Democracy and education: An introduction to the philosophy of education. New York: The Free Press.

Dick, W. \& Carey, L (1996). The systematic design of instruction. New York: Longman.

Donsky, P., \& Jones, A. (2002). CRCT scores: Atlanta first-graders do well, other grades fall. Atlanta Journal Constitution, November 13. Retrieved March 23, 2003 from http://www.accessatlanta.com/ajc/metro/atlanta/1102/14crctatlanta.html

Eaton, M. J., \& Dembo, M. H. (1997). Differences in the motivational beliefs of Asian American and nonAsian students. Educational Psychologist, 89, 433-440.

Eisenberger, R., Masterson, F.A., \& McDermitt, M. (1982). Effects of task variety on generalized effort. Journal of Educational Psychology, 74, 499-505.

Fazarro, D. E. (1999). Motivating African-American youth in technology education. Tech Directions, 59 (1), 25-27.

Fordham, S. (1993). Those loud black girls: Black women, silence, and gender 'passing' in the Academy. Anthropology and Education Quarterly, 24 (1), 3-32.

Fordham, S. (1995). Blacked out: Dilemmas of race, class, and identity at Capital High. Chicago: University of Chicago Press.

Fordham, S. (2003). Anthropologist named Anthony Professor. Currents. University of Rochester, NY. Retrieved from http://www.rochester.edu/pr/Currents/V31/V31N03/story06.html

Fordham, S. \& Ogbu, J. (1986). Black students' school success: Coping with the 'Burden of “Acting White.”' The Urban Review, 18 (3), 176-206.

Ge, X., Conger, R. D., \& Elder, G. H. (1996). Coming of age too early: Pubertal influences on girls' vulnerability to psychological distress. Child Development, 67, 3386-3499.

Green, M. (1989). Theories of human development: A comparative approach. Englewood Cliffs, NJ: Prentice-Hall.

Greeno, J.G., Collins, A.M., \& Resnick, L. (1996). Cognition and learning. In D. Berliner and R. Calfee (Eds.) Handbook of Educational Psychology, (pp. 15-46). New York: MacMillan.

Gurian, M. (2001). Boys and girls learn differently: A guide for teachers and parents. San Francisco: Jossey-Bass.

Hambleton, R. K., \& Swaminathan, H. (1985). Item response theory: Principles and applications. Boston: Kluwer-Nijhoff.

Hidi, S., \& Harackiewicz, J. (2000). Motivating the academically unmotivated: A critical issue for the $21^{\text {st }}$ Century. Review of Educational Research, 70 (2), 151-79. 
Hilliard, A. G. (1994). What good is this thing called intelligence and why bother to measure it? The Journal of Black Psychology, 20 (4), 430-444.

Hutchinson, J., Ed. (1987). New Jersey technology education curriculum project. Level 1: Introduction to technology course. New Jersey State Commission on Technology Education.

Jaworski, B. (2003). Constructivism and teaching- the socio-cultural context. Retrieved October 11, 2003 from http://www.grout.demon.co.uk/Barbara/chreods.htm.

Kemmelmeier, M. \& Oyserman, D. (2001). Gendered influence of downward social comparisons on current and possible selves. Journal of Social Issues, 57 (1), 129-148.

Kohn, A. (1993). Rewards versus learning: A response to Paul Chance. Phi Delta Kappan, 74 (10), 783787.

Kohn, A. (1994). Grading: The issue is not how but why. Educational Leadership, 52 (2), 38-41.

Ladson-Billings, G. (1994) The dreamkeepers: Successful teaching of African American children. San Francisco: Jossey-Bass.

Mercer, T. (2002). Providing students the tools to excel. Black Issues in Higher Education, 19 (10).

National Science Foundation. (1996). Women, minorities, and persons with disabilities in science and engineering. Retrieved March 21, 2003, from http://www.nsf.gov/sbe/srs/nsf00327/frames.htm

Ogbu, J. (1992). Adaptation to minority status and impact on school status. Theory into Practice, 31 (4), 287-293.

Ogbu, J. (1995). Cultural problems in minority education: Their interpretations and consequences- part one: Theoretical background. The Urban Review, 189-205.

Owens, E. W., \& Hersholt, W. C. (1998). Sex-and ethnic-related differences among high school students' technology use in science and mathematics. International Journal of Instructional Media, 25 (1), 4354.

Oyserman, D. T., \& Bybee, D. (2002). A possible selves intervention to enhance school involvement. Journal of Adolescence, 25 (3), 313-326.

Shuy, R. (1979). Is the construct intelligence a twentieth-century myth? Symposium at the American Psychological Association Annual Convention, New York.

Skinner, B.F. (1968). The technology of teaching. Englewood Cliffs, NJ: Prentice Hall.

Steele, C.M. (1997). A threat in the air: How stereotypes shape intellectual identity and performance. American Psychologist, 52 (6), 613-629.

Tapia, R., Chubin, D., \& Lanius, C. (2000). Promoting national minority leadership in science and engineering: A report on proposed actions. National Science Foundation.

U.S. Bureau of Labor Statistics. Retrieved March 21, 2003, from ftp://ftp.bls.gov/pub/special.requests/lf/aat11.txt

Van Merrienboer, J. J. G. (1997). Training Complex Cognitive Skills: A Four-Component Instructional Design Model for Technical Training. Englewood Cliffs, N.J: Educational Technology Publications.

Wells, G. (2003). Learning and teaching "Scientific Concepts": Vygotsky's ideas revisited. Retrieved October 11, 2003 from http://www.oise.utoronto.ca/ gwells/scient.concepts.txt

Wertsch, J. V. (1985). Vygotsky and the social formation of mind. Cambridge: Harvard University Press.

Wilson, A. (1991) Awakening the natural genius of black children. New York: Afrikan World Infosystems.

Wink, J., Putney, L. G. (2002). A vision of Vygotsky. Boston: Allyn and Bacon.

Woodson, C. G. (1991). The mis-education of the negro. New York: Afrikan World InfoSystems. 


\section{Appendix}

\section{Abbreviated Curriculum for Four Week Period}

\section{Week 1}

Tu- Introductions (me, them), if they all know each other, get them to say why they want to be in the class (20 minutes)

Overview of the class and what we will be doing (15 minutes)

Vocab. Lecture: Computer, file, program, network, (15 minutes)

Reflection - “What are your expectations for this class?” (10 minutes)

Th- Vocab. Lecture: Computer, file, program (Review), operating system, GUI (new) (15 minutes)

Demo/Exercise - Demonstrate the operation of the Windows 95 desktop and how they can get around in it. Identify several of the applications: word processor, Web browser. Have them create a simple text file (explain what this is), save it, re-open it. If this is too simple for the more advanced students, have them show the less advanced ones how. (20 minutes)

Discussion, Q/A “Why do you think it's easier to use a GUI than text” (15 minutes)

Reflection: describe your activities in class today. What is a program? What is an operating system? What is a file? What is a GUI? Scaffold them with a cheat sheet if required. (10 minutes)

\section{Week 2}

Tu- Vocab. Lecture: Operating system, file, GUI (review); network, Internet, protocol (new) (15 minutes)

Demo/Exercise - Start computer, let them log on with their IDs and passwords; high level description of networking; high level description of the Internet; identify the Web browser; briefly explain its operation; explain briefly the origins of the WWW. (20 minutes)

Discussion, Q/A:" What are the possibilities when you can connect different computers together?” (15 minutes)

Reflection: Describe your activities in class today. What is a network? What is the Internet? What is the World Wide Web? (10 minutes)

Th- Vocab. Lecture: Network, Internet, protocol (review); World Wide Web, Hyper Text Transfer Protocol, Hyper Text Markup Language (new) (15 minutes)

Demo/Peer Tutoring - They should be able to log on without too much prompting by now (scaffold if needed); give a simple demonstration of HTML (tags); show them how to create a simple HTML text file in a word processor, load it locally in the browser, and let them see it rendered; have them change the text, re-save the file, and re-render it. Give a brief, high-level explanation of how HTTP allows HTML to work. Allow more advanced peers to tutor less advanced peers. Observe and notate. (20 minutes)

Discussion, Q/A (15 minutes)

Reflection: Describe your activities in class today. What is a network? What is the Internet? What is the World Wide Web? (10 minutes) 


\section{Week 3}

Tu- Vocab. Lecture Internet, protocol, World Wide Web, HTML(review); File Transfer Protocol (FTP), server, Web server (new) (15 minutes)

Demo/Exercise - Demonstrate for them how to move a file from a workstation to a Web server and verify that the file was retrieved (in this they will learn something about file structures in general); have them create some HTML text on their workstation, move it to the Web server, render the file in their local Web browser, change it, see the edited file rendered.(20 minutes)

Discussion, Q/A “Why is it beneficial to move files from one computer to another?” (15 minutes)

Reflection: Describe your activities in class today. What is a protocol? What is the file transfer protocol? What is a server? (10 minutes)

Th- Vocab. Lecture: File Transfer Protocol (FTP), server, Web server (review); Transmission Control Protocol/Internet Protocol (TCP/IP)(new) (15 minutes)

Demo/Peer Tutoring - A continuation of the previous session's demonstration of moving files back and forth around the Internet, but including a "high level" discussion of TCP/IP. It is important not to overwhelm the students with technical details- they have years to fill in the details. This discussion should be in the broadest and most digestible terms. It may seem that the TCP/IP discussion should have preceded several of the other topics. It is done this way to "back into" the more profound concepts of internetworking- that is, the importance of a standard transmission protocol. Allow more advanced peers to tutor less advanced peers. Observe and notate. (20 minutes)

Discussion, Q/A: What good is a "standard protocol?" Is that what the Internet uses? (15 minutes)

Reflection: Describe your activities in class today. Describe your activities in class today What is TCP/IP? (10 minutes)

\section{Week 4:}

Tu- Demo- Imbedding graphics in Web pages- Take a digital picture of each student (using a digital camera with a floppy disk for simplicity) show the students how to transfer it to their desired location, then show them how to define the tag to render the graphic). (15 minutes).

Peer Tutoring: Allow the students to work with each other practicing uploading the picture to their desired directory and creating the HTML tags required to render it in a browser. Direct them into creating simple informational pages about themselves. Allow more advanced peers to tutor less advanced peers. Observe and notate. (20 minutes).

Discussion, Q/A: What do you see as the benefits of what we have learned so far (15 minutes).

Reflection: Describe your activities in class today (10 minutes).

Th- Demo- Very brief demo of how to use clip art in Web pages. Explain that there are tools with which the students can create their own graphics (like Photoshop), but time prevents us from talking a lot about them. Show them where to find clip art (when they have a live Internet connection, for now provide them with a CD with clip art on it). By now they should be able to move the files from the CD to where they want them.(15 minutes). 
Peer Tutoring: Allow students to work with each other on their pages and create whatever their skills allow them to create. Allow more advanced peers to tutor less advanced peers. Visit each group of students and discuss with them what they are doing as they work. Observe and notate. (30 minutes).

Reflection: Describe your experiences in this class over the past several weeks. (15 minutes).

\section{Biography}

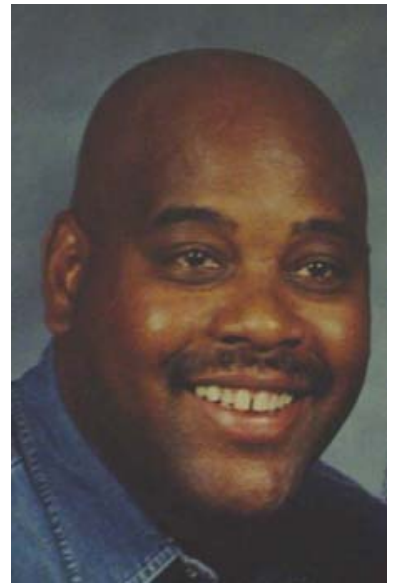

Cameron Seay is a candidate in the doctoral program for educational psychology at Georgia State University in Atlanta, Georgia, USA. His research interests include technology diffusion, the epistemology of information technology and technology expertise development and assessment. His academic background includes advanced degrees in computer information systems, business, and economics, and he has worked as an IT professional in various capacities for the past 17 years. The defense of his dissertation is scheduled for March of 2004, and he looks forward to working as a research professor studying the relationship between technology and education. 